\title{
Parental child-feeding strategies in relation to Dutch children's fruit and vegetable intake
}

\author{
Gertrude G Zeinstra ${ }^{1, *}$, Maria A Koelen², Frans J Kok ${ }^{1}$, Nynke van der Laan ${ }^{1}$ and \\ Cees de Graaf ${ }^{1}$ \\ 'Division of Human Nutrition, Wageningen University, 6700 EV Wageningen, The Netherlands: ${ }^{2}$ Department of \\ Communication Science, Wageningen University, Wageningen, The Netherlands
}

Submitted 12 August 2008: Accepted 11 August 2009: First published online 22 September 2009

\begin{abstract}
Objective: To identify parental child-feeding strategies that may increase children's fruit or vegetable intake, since the relationship between these strategies and children's intake has never been investigated for fruit and vegetables as two separate food groups.

Design: A survey study, where parents provided information about their practices in relation to feeding their children and about their own and their children's fruit and vegetable intake. Children completed a preference questionnaire about fruit and vegetables. To find underlying parental child-feeding strategies, factor analysis was applied to parents' practices in relation to fruit and vegetables separately. Regression analysis was used to predict the effect of these strategies on children's fruit and vegetable intake. The impact of the strategies was further analysed by estimating children's intake based on the frequency of use of specific strategies.

Setting: The study was conducted at three primary schools in The Netherlands.

Subjects: A total of 259 children between 4 and 12 years old and their parents ( $n$ 242). Results: Parents used different strategies for fruit as compared with vegetables. The vegetable-eating context was more negative than the fruit-eating context. Parental intake and presenting the children with choice were positive predictors of children's intake of both fruit and vegetables. The intake difference based on frequency of use of the strategy 'Choice' was $40 \mathrm{~g} / \mathrm{d}$ for vegetables and $72 \mathrm{~g} / \mathrm{d}$ for fruit $(P<0 \cdot 001)$. Conclusions: Future interventions should focus on presenting children with choice during fruit- and vegetable-eating situations, since this is a powerful strategy to stimulate children's fruit and vegetable intake.
\end{abstract}

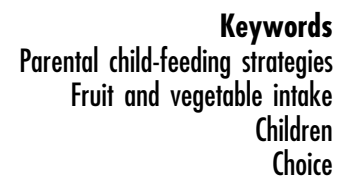

Parents play an important role in children's food intake: they make foods available and accessible for the child and they act as role models ${ }^{(1-4)}$. Parents also create the social eating environment by the use of parental childfeeding (PCF) strategies, such as rules, table food management and verbal instructions ${ }^{(1,5,6)}$. There is substantial evidence that such child-feeding strategies influence children's eating ${ }^{(5)}$. Although parents use these strategies with the best intentions, research has shown that the effects of these parental strategies on children's food intake are not always in the intended direction.

Modelling, mere exposure, verbally rewarding for eating, increasing the availability and accessibility of food and using foods as rewards for good behaviour are strategies that have proved effective in increasing intake of specific foods ${ }^{(2,3,6-10)}$. Restricting the intake of unhealthy food and giving health information about a product appear to foster an unhealthy eating pattern ${ }^{(11-14)}$. Pressuring a child to eat and offering rewards using instrumental eating ('If you eat your spinach, you will get a dessert') also decrease children's intake or preferences ${ }^{(9,13,15,16)}$. However, the consequences of these strategies appear to be less straightforward, since pressure and reward may have positive effects under appropriate circumstances ${ }^{(17-20)}$. Offering unfamiliar foods with a familiar topping or providing the child with taste information can increase children's willingness to taste ${ }^{(21,22)}$.

The use and role of PCF strategies in relation to food consumption is usually studied with fruit and vegetables as one food category ${ }^{(2,8,23)}$. Since fruit and vegetables vary considerably in taste, energy content and consumption moment, parents may use different strategies for fruit as compared with vegetables. Additionally, the relationship between parental strategies and children's intake may depend on whether fruit or vegetables are involved. 
The aims of the present study were to: (i) investigate which PCF strategies Dutch parents use to stimulate their children to eat fruit or vegetables; (ii) determine how frequently these strategies are used; and (iii) examine the relationship between these strategies and children's intake of, and preference for, fruit and vegetables. Fruit and vegetables were analysed as two distinct food groups. We strove to reveal strategies that have the potential to increase primary-school-aged children's fruit or vegetable intake.

\section{Methods}

\section{Subjects}

Participants were recruited via three primary schools in three Dutch cities (Wageningen, Franeker and Zeewolde) in order to include participants from various backgrounds. The participants consisted of children of varying ages to ensure that the whole range of primary school was included ( $4-5$ years, 7-8 years and 11-12 years) and their parents. At each school, three classes participated in the study, one class per age group.

All parents of the participating classes (280) were invited to participate. Those children whose parents signed an informed consent form were included in the study. Two hundred and sixty parents (93\%) signed the informed consent for themselves and their child/children and 242 parents (86\%) returned the questionnaire. The response rate for the children was 93\% (259 children).

\section{Study design}

The study protocol was approved by the Medical Ethical Committee of Wageningen University. Parents completed a booklet with questions about four topics: (i) their practices in relation to feeding fruit and vegetables to their children; (ii) fruit and vegetable intake of the parent and child; (iii) parental control practices; and (iv) demographic variables. The parent most involved in family eating was requested to fill in the booklet. The children completed a preference questionnaire concerning fruit and vegetables.

\section{Parent-reported variables}

Parental child-feeding strategies

Various questions were asked about specific, practical behaviours that parents can apply to influence their children's food choice. These practical actions are defined as parental practices ${ }^{(23)}$. We use the term 'strategies' to indicate the more general concepts underlying the practices.

To our knowledge, there are no questionnaires available that focus on fruit or vegetables separately in a comprehensive way. Therefore, we developed a PCF strategies questionnaire on the basis of existing questionnaires ${ }^{(2,18,23-26)}$. One set of questions was adjusted for fruit-eating situations (thirty-five practices) and another for vegetable-eating situations (forty practices). Four additional questions were included for vegetables with regard to adding sauces. Response categories were on a 5-point scale where $1=$ 'never', $2=$ 'rarely', $3=$ 'sometimes', $4=$ 'often' and $5=$ 'always'. The questionnaire was improved after a pre-test on twenty parents (not participants).

\section{Fruit and vegetable intake}

The eight-item FFQ of Bogers et al. was used to determine fruit and vegetable intake of parents and children. This FFQ is validated in mothers aged $29-50$ years with vitamin $C$ and carotenoids as biomarkers $^{(27)}$, and has been used in further research to assess fruit and vegetable intake of parents and their children ${ }^{(28,29)}$. Parents completed the questions for themselves and their child. They were asked to report their average intake frequency during the previous month and their usual portion size. Standard portion sizes were used to calculate intake in grams ${ }^{(30)}$.

\section{Child Feeding Questionnaire}

Parents completed the parental control sections of the Child Feeding Questionnaire (CFQ) ${ }^{(24)}$ : 'Monitoring', 'Restriction' and 'Pressure to eat'. Questions were on a 5point scale from $1=$ 'disagree' to $5=$ 'agree' or from $1=$ 'never' to $5=$ 'always'.

\section{Demographic variables}

Parents completed questions about their age, gender, educational level and the educational level of their partner.

\section{Child-reported variables}

\section{Preference questionnaire}

The questionnaire consisted of photographs of twenty-four products from five product categories: fruits, vegetables, fruit juices, neutral products and energy-dense products. There were eight fruit types, eight vegetable types and the two fruit juices most frequently consumed by Dutch children ${ }^{(31)}$. Carrots were included twice (raw and cooked), because both forms are frequently eaten and differ in liking ${ }^{(32)}$. To enable a comparison, three neutrally tasting products (potatoes, bread and milk) and two energy-dense products (chocolate and French fries) were included.

The response format was a 5-point smiley scale ranging from $1=$ 'dislike a lot' to $5=$ 'like a lot' along with the option 'never tried'. This format has been used successfully in other studies with children ${ }^{(33,34)}$. A pre-test with eight children (not participants) confirmed comprehensibility.

\section{Procedures}

Parents received the questionnaire booklet at home and returned the completed booklet to their child's teacher.

The child sessions were performed at school during regular school hours. To ensure consistency in the instructions during data collection, an instruction sheet was developed for these sessions.

The youngest children ( $4-5$ years) were guided individually in a separate, quiet room. After practising the smiley 
scale, the researcher assisted the child with completing the preference questionnaire. The other two age groups completed the preference questionnaire in their own classroom following the instructions of the researchers, who were available for assistance. Each individual session and each classroom session took about $15 \mathrm{~min}$.

\section{Statistical analyses}

All statistical analyses were performed with the SPSS statistical software package version $12 \cdot 0 \cdot 1$ (SPSS Inc., Chicago, IL, USA). The child questionnaire and parental booklet had pre-assigned identical codes to link the child-parent couples. Three child-parent couples were excluded from the fruit analysis because the children were allergic to fruit. Children's mean preference scores were calculated for each of the five product categories.

When more than 20\% of the parent-reported intake questions were missing, the subject received a missing value for intake of that category. When $20 \%$ or less were missing, 'frequency' and 'portion size' were replaced by the mean population value. This replacement procedure was applied for twenty-five parents (10\%) and seventeen children $(7 \%)$ to calculate their fruit intake.

Exploratory principal component analysis (PCA) with varimax rotation was applied to the forty PCF practices for vegetables and the thirty-five practices for fruit to find underlying PCF strategies. Factor loadings of 0.50 were assumed practically significant and an internal consistency (Cronbach's alpha) of 0.60 was considered sufficient for exploratory research ${ }^{(35)}$. In addition, the final factor structures were based largely on the interpretation of the factors. Factor values were calculated as the mean score of the items comprising the factor.

To investigate the predictive value of the different strategies on children's fruit and vegetable intake and preference, we performed a stepwise multiple regression analysis. To further analyse the impact of a particular strategy, tertiles were composed based on parental use of the particular strategy. For each tertile, children's fruit or vegetable intake was estimated. ANOVA with Bonferroni as post hoc test was used to compare the tertiles.

Pearson correlation coefficients were calculated between 'Monitoring', 'Restriction' and 'Pressure to eat' (CFQ) and the fruit and vegetable strategies specific to our study, in order to explore validity. Correlation coefficients above $0 \cdot 25$ were regarded as relevant.

For all analyses, a $P$ value $\leq 0.05$ was considered significant.

\section{Results}

\section{Demographic characteristics}

The demographic characteristics of the study population are shown in Table 1. Mainly mothers completed the parental booklet. Less educated parents were under-represented.
Table 1 Demographic characteristics of the study population in which the association between parental child-feeding strategies and children's fruit and vegetable intake was studied (242 parents and 259 children)*

\begin{tabular}{lrr}
\hline Characteristic/category & $n$ & $\%$ \\
\hline School & & \\
Wageningen & 77 & 30 \\
Franeker & 107 & 41 \\
Zeewolde & 75 & 29 \\
Gender of child & 132 & 51 \\
$\quad$ Boy & 127 & 49 \\
Girl & & \\
Age group & 99 & 38 \\
4-5 years & 84 & 32 \\
7-8 years & 76 & 29 \\
11-12 years & & \\
Gender of parent & 24 & 10 \\
Male & 216 & 90 \\
Female & & \\
Educational level of parent & 110 & 46 \\
$\quad$ High & 114 & 48 \\
Middle & 15 & 6 \\
Low & & \\
Educational level of parent's partner & 115 & 50 \\
High & 86 & 38 \\
Middle & 27 & 12 \\
Low &
\end{tabular}

*Due to missing data, totals can be lower than 242 or 259.

Children's participation rates were high for all three schools: Franeker 94\% (107/114); Wageningen $97 \%$ (77/ 79); Zeewolde $86 \%(75 / 87)$.

\section{Liking}

Children's liking for vegetables $($ mean $=3 \cdot 1 ; \mathrm{SD}=0 \cdot 9)$ was the lowest, followed by the neutral product group $($ mean $=3 \cdot 8 ; \mathrm{SD}=0 \cdot 8)$. Preference for fruit $($ mean $=4 \cdot 0$; $\mathrm{SD}=0 \cdot 7)$ and fruit juice $($ mean $=4 \cdot 0 ; \mathrm{SD}=1 \cdot 0)$ was similar. The energy-dense products (chocolate and French fries) were the most appreciated by the children $($ mean $=4 \cdot 6 ; \mathrm{SD}=0 \cdot 6)$.

\section{Factor analysis}

The PCA on the PCF practices for vegetables yielded eight factors $\left(R^{2}=52 \%\right.$; see Appendix 1). Six factors had an internal consistency acceptable for exploratory research (Cronbach's $\alpha>0 \cdot 60$; see Table 2) and were used for further analyses. Eleven of the forty practices for vegetables were not included because ten did not load highly on any of the factors and one loaded moderately highly on two factors. We labelled the six acceptable PCF strategies for vegetables as: 'Positive information', 'Distraction', 'Choice', 'Negative atmosphere', 'Pressure' and 'Taste masking'.

The PCA on the PCF practices for fruit yielded five factors $\left(R^{2}=44 \%\right.$; see Appendix 2). One factor did not have an acceptable internal consistency $(\alpha=0.54$; see Table 2) and was therefore omitted from further analyses. Thirteen of the thirty-five items for fruit were not included since they did not load highly on any of the factors. The 
four acceptable factors for fruit were labelled as 'Negative atmosphere and Pressure', 'Positive information', 'Choice' and 'Availability'.

Although the PCF practices for both fruit and vegetables were almost identical in the questionnaire, factor analyses showed some differences in the underlying structure. 'Pressure' and 'Negative atmosphere' were separate PCF strategies for vegetables, whereas they belonged to one strategy for fruit. 'Availability' was an acceptable factor for fruit, whereas this strategy did not emerge as a separate factor for vegetables. 'Choice' for fruit seemed to focus on

Table 2 Mean factor values, standard deviation and Cronbach's alpha for the parent-reported parental child-feeding (PCF) strategies for fruit and vegetables separately*

\begin{tabular}{|c|c|c|c|}
\hline \multirow[b]{2}{*}{ PCF strategy } & \multicolumn{3}{|c|}{ Vegetables ( $n$ 242) } \\
\hline & Mean & SD & $\alpha \dagger$ \\
\hline Positive information $\ddagger$ & $4 \cdot 0$ & 0.7 & 0.84 \\
\hline Negative atmosphere & $2 \cdot 6$ & 0.8 & 0.80 \\
\hline Pressure & $3 \cdot 4$ & 0.9 & $0 \cdot 76$ \\
\hline Choice & $2 \cdot 1$ & 0.6 & $0 \cdot 70$ \\
\hline Distraction & $1 \cdot 7$ & 0.7 & 0.67 \\
\hline Taste masking & $1 \cdot 6$ & 0.6 & 0.62 \\
\hline Extra vegetables§ & $2 \cdot 9$ & $0 \cdot 8$ & 0.59 \\
\hline \multirow[t]{3}{*}{ Habit§ } & $4 \cdot 8$ & $0 \cdot 4$ & 0.42 \\
\hline & \multicolumn{3}{|c|}{ Fruit (n 239) } \\
\hline & Mean & SD & $\alpha \|$ \\
\hline Negative atmosphere and Pressure & $2 \cdot 0$ & 0.7 & 0.85 \\
\hline Positive information & $3 \cdot 8$ & 0.7 & 0.82 \\
\hline Availability & $4 \cdot 8$ & 0.4 & 0.66 \\
\hline Choice & $3 \cdot 6$ & 0.6 & $0 \cdot 60$ \\
\hline Distraction§ & $1 \cdot 3$ & 0.4 & 0.54 \\
\hline
\end{tabular}

*Response categories were on a 5 -point scale where $1=$ 'never', 2 = 'rarely', $3=$ 'sometimes', $4=$ 'often' and $5=$ 'always'.

tn 238 to 242 .

$\ddagger n 240$.

$\S$ Excluded from further analyses, due to low Cronbach's $\alpha(<0 \cdot 60)$.

IIn 233 to 239. child participation, whereas for vegetables the focus was more on making a choice possible. For vegetables, 'Distraction' included instrumental eating and positive, playful practices; for fruit, this strategy was not reliable. The composition of the strategy 'Positive information' was exactly the same for fruit and vegetables.

The mean factor scores for each PCF strategy for fruit and vegetables are shown in Table 2. 'Positive information' and 'Pressure' were the strategies most frequently applied for vegetables. 'Taste masking' and 'Distraction' were the least used strategies for vegetables. For fruit, 'Availability' was the most used PCF strategy, followed by 'Positive information' and 'Choice'.

\section{Relationship between parental child-feeding strategies and children's intake}

The final regression model explained $47 \%$ of the variance in children's vegetable intake. The model included seven variables, shown in Table 3. 'Distraction', 'Negative atmosphere' and 'Positive information' were negative predictors of children's vegetable intake. 'Parental vegetable intake', 'Choice', 'Pressure' and 'Age 7-8 years or 11-12 years' were positive predictors of vegetable intake.

The regression model for children's fruit intake included three variables, which accounted for $28 \%$ of the variance (Table 3). 'Parental fruit intake' and 'Choice' were positive predictors of children's fruit intake, whereas 'Negative atmosphere and Pressure' was a negative predictor.

The regression models to predict children's preference explained a much smaller amount of variance: $3 \%$ for vegetables and $18 \%$ for fruit (results not shown). However, both models included the PCF strategy 'Choice' as a significant positive predictor.

\section{Additional analyses}

Additional analyses were conducted with the PCF strategies that were positive predictors of children's intake.

Table 3 Final stepwise multiple regression model for children's vegetable $\left(R^{2}=47 \%\right)$ and fruit intake $\left(R^{2}=28 \%\right)$ with parental childfeeding strategies, age and parental intake as independent variables

\begin{tabular}{|c|c|c|c|c|c|}
\hline & \multicolumn{2}{|c|}{ Unstandardized coefficients } & \multirow{2}{*}{$\begin{array}{c}\text { Standardized coefficients } \\
\beta\end{array}$} & \multirow[b]{2}{*}{ Significance } & \multirow[b]{2}{*}{$R^{2}(\%)$} \\
\hline & $B$ & SE & & & \\
\hline \multicolumn{6}{|l|}{ Predictors of vegetable intake } \\
\hline Parental vegetable intake & 0.28 & 0.03 & 0.45 & 0.00 & $24 \cdot 9$ \\
\hline Choice & $25 \cdot 1$ & $4 \cdot 72$ & 0.28 & 0.00 & $8 \cdot 4$ \\
\hline Distraction & $-11 \cdot 1$ & 4.98 & $-0 \cdot 13$ & 0.03 & $5 \cdot 7$ \\
\hline $\begin{array}{l}\text { Dummy variable age (Age } \\
4-5 \text { years }=0 ; \text { Age } 7-8 \\
\text { years and } 11-12 \\
\text { years }=1 \text { ) }\end{array}$ & $15 \cdot 1$ & $6 \cdot 50$ & $0 \cdot 13$ & 0.02 & $2 \cdot 1$ \\
\hline Negative atmosphere & $-13 \cdot 7$ & $4 \cdot 13$ & -0.19 & 0.00 & 1.9 \\
\hline Pressure & $13 \cdot 4$ & 3.57 & $0 \cdot 21$ & 0.00 & $2 \cdot 8$ \\
\hline Positive information & $-10 \cdot 8$ & $4 \cdot 52$ & $-0 \cdot 13$ & $0 \cdot 02$ & $1 \cdot 5$ \\
\hline \multicolumn{6}{|l|}{ Predictors of fruit intake } \\
\hline Parental fruit intake & 0.37 & 0.05 & 0.45 & 0.00 & $23 \cdot 3$ \\
\hline Choice & $30 \cdot 7$ & $10 \cdot 73$ & $0 \cdot 17$ & 0.01 & $3 \cdot 4$ \\
\hline $\begin{array}{l}\text { Negative atmosphere and } \\
\text { Pressure }\end{array}$ & $-18 \cdot 1$ & 8.92 & $-0 \cdot 12$ & 0.04 & $1 \cdot 3$ \\
\hline
\end{tabular}



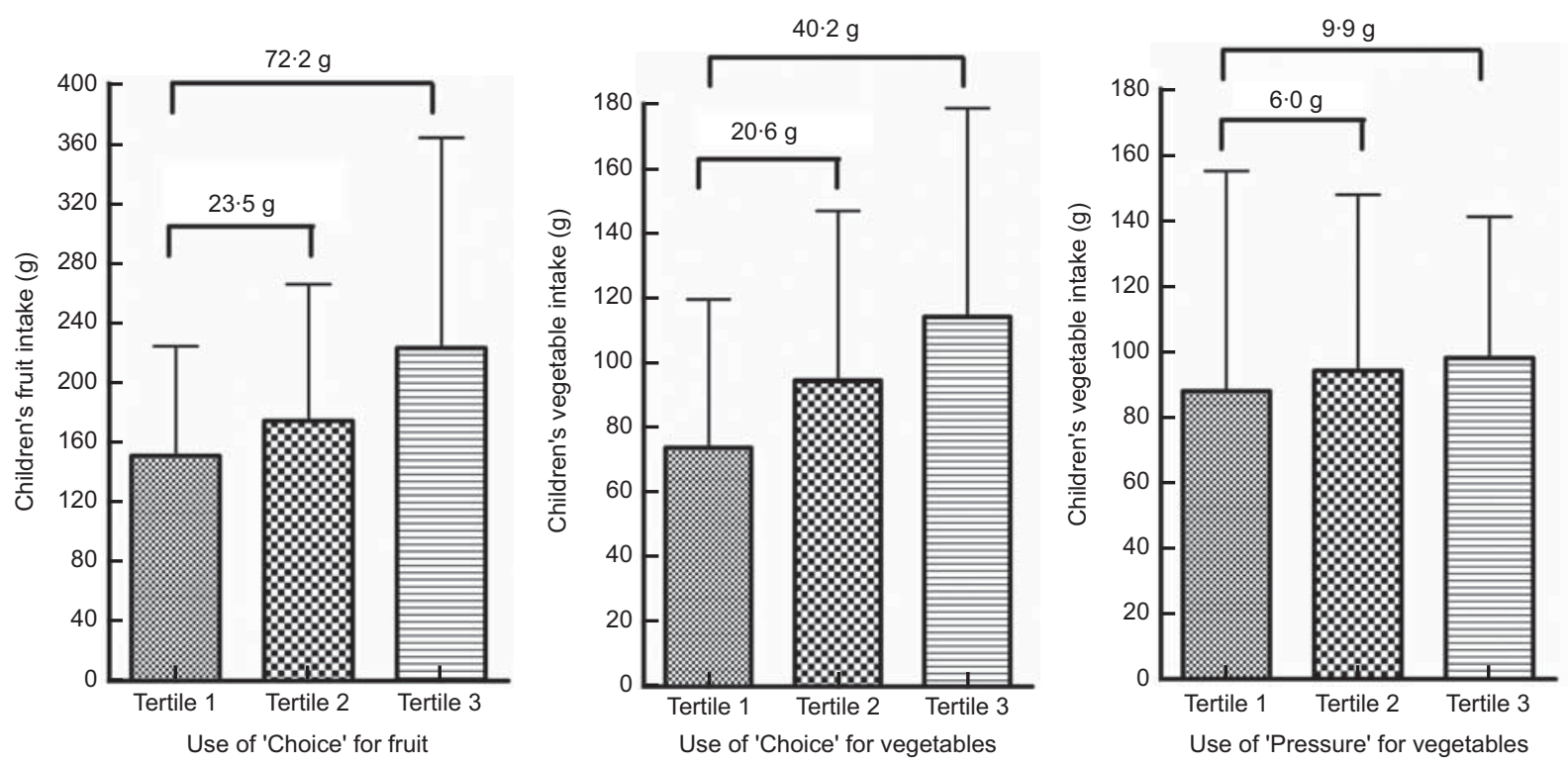

Fig. 1 Comparison of children's vegetable or fruit intake between the tertiles ( $n 72$ to 84 ) of three parental child-feeding strategies (response categories were on a 5-point scale where $1=$ 'never', 2 = 'rarely', 3 = 'sometimes', $4=$ 'often' and $5=$ 'always'): 'Choice' for fruit; 'Choice' for vegetables; and 'Pressure' for vegetables. Tertiles are based on the frequency of use of the specific parental child-feeding strategy. $P$ values for comparisons between the three tertiles (ANOVA plus Bonferroni) as follows. 'Choice' for fruit $(P<0.001)$ : tertile 1 v. $2, P=0.52$; tertile 1 v. 3, $P<0.001$; tertile 2 v. $3, P=0.02$. 'Choice' for vegetables $(P<0.001)$ : tertile 1 v. 2 , $P=0.06$; tertile 1 v. $3, P<0.001$; tertile 2 v. $3, P=0.09$. 'Pressure' for vegetables $(P=0.56)$

Since it is unlikely that parents use these strategies more because their children eat already large quantities of fruit or vegetables, it seems plausible that a high use of these strategies results in a higher intake. For that reason, tertiles were made based on the use of the strategies 'Choice' and 'Pressure' for vegetables, and 'Choice' for fruit. The differences in children's intake between the tertiles were calculated to estimate the impact of the particular strategy.

Figure 1 shows that there is no significant difference in children's vegetable intake between the three tertiles for 'Pressure' $(P=0.56)$. For the strategy 'Choice', the difference in children's intake between the lowest and highest tertile was $40 \mathrm{~g} / \mathrm{d}$ for vegetables $(P<0 \cdot 001)$ and $72 \mathrm{~g} / \mathrm{d}$ for fruit $(P<0 \cdot 001)$. The mean use of 'Choice' for vegetables in the highest tertile was $2 \cdot 8$ compared with 1.4 in the lowest tertile, whereas for fruit, these values were $4 \cdot 2$ and $3 \cdot 0$ on a 5 -point scale.

\section{Relationship between parental child-feeding strategies and Child Feeding Questionnaire}

For vegetables, CFQ 'Restriction' was positively correlated with the PCF strategies 'Distraction' $(r=0 \cdot 37 ; P<0 \cdot 001)$ and 'Negative atmosphere' $(r=0 \cdot 28 ; \quad P<0 \cdot 001)$. CFQ 'Pressure to eat' was positively related to the PCF strategies 'Distraction' $(r=0 \cdot 40 ; \quad P<0 \cdot 001)$, 'Negative atmosphere' $(r=0.38 ; P<0 \cdot 001)$ and 'Pressure' $(r=0.27 ; P<0 \cdot 001)$.

For fruit, the PCF strategy 'Negative atmosphere and Pressure' was positively associated with the CFQ factors 'Restriction' $(r=0.37 ; \quad P<0.001)$ and 'Pressure to eat' $(r=0.39 ; P<0 \cdot 001)$.

\section{Discussion}

Our study showed that parents applied different strategies for fruit compared with vegetables. For fruit, 'Availability', 'Positive information' and 'Choice' were the most used, which all seem positive strategies. For vegetables, 'Positive information' and 'Pressure' were the most used strategies, making the vegetable-eating context more negative than the fruit-eating context. This difference in use of strategies could be due to differences in cultural habits $^{(36)}$ or to a difference in liking: parents may use different strategies because their children like fruit but dislike vegetables ${ }^{(33,37)}$.

The strategies 'Negative atmosphere', 'Distraction' and 'Positive information' were negatively related to children's vegetable intake. This could mean that parents use these PCF strategies often because their child does not want to eat vegetables, but it could also indicate that the use of these strategies results in a low vegetable intake. Similarly for fruit: frequent use of the strategy 'Negative atmosphere and Pressure' could be caused by a child's low fruit intake or could lead to a lower fruit intake. Hence, the use of a particular strategy may be the cause or the consequence of low consumption. Further research is needed to investigate the direction of these relationships.

It was remarkable that 'Pressure' was positively related to children's vegetable intake, whereas this strategy was negatively related to fruit intake, although for fruit, 'Pressure' formed one strategy together with 'Negative atmosphere'. In the literature, negative correlations are 
often found between pressure and intake, although Wind et $a{ }^{(20)}$ found a positive correlation as well between parental demand ( pressure) and children's vegetable intake. Presumably, the impact of a particular strategy on children's intake depends on the product in question. The fact that children preferred fruits above vegetables may be the reason for this contrasting finding. Consumption of disliked products, such as vegetables, may need some pressure, whereas liked products, such as fruits, may not need pressure. Variation in product liking may partly explain the different results in the literature regarding intake and pressuring strategies ${ }^{(13,16,18,20)}$.

Parental intake and the PCF strategy 'Choice' were the strongest positive predictors of children's intake for both fruit and vegetables. Modelling, genetic similarity and similar food availability have been suggested to account for the strong influence of parental intake ${ }^{(13,38)}$.

'Choice' as a potential strategy to promote children's fruit and vegetable intake is a new finding. A high use of 'Choice' compared with a low use of 'Choice' is associated with a higher daily intake of $40 \mathrm{~g}$ of vegetables and $72 \mathrm{~g}$ of fruit, corresponding to $27 \%$ of the recommended vegetable intake for children and 36\% for fruit. Additionally, 'Choice' was a positive predictor of children's preference for both fruit and vegetables. The potentially powerful role of 'Choice' is in accordance with motivation theories. Choice gives children a feeling of autonomy, and this enhances their intrinsic motivation ${ }^{(39)}$. It has indeed been shown that food liking scores in adults are higher when there is some degree of choice compared with no-choice conditions $^{(40)}$. Although children themselves often state that they dislike being 'preached to' and want to have some autonomy over their food behaviour ${ }^{(41,42)}$, this strategy does not receive much attention in interventions. Especially for vegetables, there is room for improvement in the use of 'Choice', since the mean use in the highest tertile in our study was only $2 \cdot 8$ on a 5 -point-scale.

The results concerning pressure can be viewed in the light of motivation theories as well. Eating vegetables is not intrinsically satisfying or enjoyable for children, so they need an external motivation (pressure) to eat them. In contrast, fruit is liked, thus eating fruit is an enjoyable activity in itself. External controllers, such as parental pressure, can result in reactance or diminish children's internal motivation for eating fruit ${ }^{(39,41)}$. More research is needed to investigate how pressure works in the long term.

In view of general parenting styles, the strategy 'Pressure' for fruit or vegetables probably fits into an authoritarian style, which is typified by extensive external control, strict discipline, little responsiveness ${ }^{(18,25)}$ and which is positively associated with 'Restriction' and 'Pressure to eat' ${ }^{(42)}$. 'Restriction' and 'Pressure to eat' were positively correlated to our strategies 'Pressure' for vegetables and 'Negative atmosphere and Pressure' for fruit, strengthening the abovementioned assumption. 'Distraction' for vegetables was also positively correlated to 'Restriction' and 'Pressure to eat', suggesting that 'Distraction' is a type of external control as well.

'Choice' may fit into an authoritative style, which is characterized by warmth, responsiveness, setting limits without controlling, reasoning, some flexibility and which has been related to more positive child outcomes ${ }^{(18,25)}$. In our study, 'Choice' was neither for fruit nor for vegetables correlated with 'Restriction', 'Pressure to eat' or 'Monitoring', indicating that this is a distinct concept that deserves further attention.

\section{Limitations and strengths}

Interpretation of our findings should take the limitations into account. First, the data are cross-sectional, so no conclusions can be drawn about cause and effect. Longitudinal studies and experimental work is required to elucidate cause and effect.

Another limitation is that the data about intake and the strategies were self-reported, which may have led to socially desirable answers. Besides, parents may not always be consciously aware of how often they use specific practices with regard to fruit and vegetables. Parents completed the questions about their children's fruit and vegetable consumption, which may have led to under- or overestimation. The alternative, an observational study, would be impossible in practical terms with this number of participants.

For future research, the validity and reproducibility of our PCF strategies questionnaire for fruit and for vegetables should be assessed. The correlations between our strategies and the parental control practices of the CFQ ${ }^{(24)}$ give initial support for the validity of our questionnaire.

Although we tried to include subjects from various educational backgrounds, the research population consisted mainly of more highly educated people. Since fruit and vegetable intake as well as parental use of strategies may differ by educational level ${ }^{(8,43)}$, future studies should also include parents with a lower educational background.

Because the fruit and vegetable intake data are validated to rank order individuals according to their intakes $^{(27)}$, we have to be careful with conclusions about the absolute quantities for intake.

Yet, this study has important strengths. First, we studied the role of parental strategies in relation to fruit and vegetables separately, which has not been done before. Furthermore, we did not use a pre-determined factor structure, but extracted the underlying strategies from the data themselves. Finally, the high response rate is a strength. Comprehensible, timely information, thorough preparation by the research team, enthusiastic teachers and an up-todate, hot topic have probably led to this high response rate.

\section{Conclusion and recommendations}

We aimed to identify strategies that have the potential to increase primary-school-aged children's fruit or vegetable 
consumption. Our study showed that a high parental intake and giving children choice are promising strategies to encourage children's fruit and vegetable intake. Healthy eating programmes should make a distinction between fruit and vegetables, since there is a difference in how they are handled at home. Using pressure to encourage the child to eat some vegetables every day can be beneficial for children's vegetable intake, whereas this is not true for fruit. However, providing the child with choice has a much greater potential to stimulate fruit and vegetable intake and deserves more attention. To encourage children's fruit and vegetable intake in the long term, a positive eating atmosphere where children have some autonomy over their food choices will be most advantageous.

\section{Acknowledgements}

Sources of funding: The present study is part of G.G.Z.'s $\mathrm{PhD}$ project, which is funded by Wageningen University, Graduate School VLAG and Mansholt Graduate School. Conflict of interest declaration: There are no conflicts of interest. Authorship responsibilities: All authors were involved in the design of the study. G.G.Z. and N.v.d.L. collected the data. G.G.Z. was responsible for the data analysis with assistance and input from the other authors. All authors contributed to the discussion of the results. G.G.Z. wrote the manuscript with critical input from all authors. Acknowledgements: We would like to thank the directors and teachers of the schools for their time and hospitality. In addition, we would like to thank the children and their parents for their participation. Jeny Schrotenboer and Trienika Luth are gratefully acknowledged for their practical assistance. Finally, we appreciated Catherine O'Dea's contribution to the manuscript.

\section{References}

1. Birch LL \& Fisher JO (1998) Development of eating behaviors among children and adolescents. Pediatrics 101, 539-549.

2. Cullen KW, Baranowski T, Rittenberry L, Cosart C, Hebert D \& de Moor C (2001) Child-reported family and peer influences on fruit, juice and vegetable consumption: reliability and validity of measures. Health Educ Res 16, 187-200.

3. Fisher JO, Mitchell DC, Smiciklas-Wright H \& Birch LL (2002) Parental influences on young girls' fruit and vegetable, micronutrient, and fat intakes. J Am Diet Assoc 102, 58-64.

4. Nicklas TA, Baranowski T, Baranowski JC, Cullen K, Rittenberry L \& Olvera N (2001) Family and child-care provider influences on preschool children's fruit, juice, and vegetable consumption. Nutr Rev 59, 224-235.

5. Ventura AK \& Birch LL (2008) Does parenting affect children's eating and weight status? Int J Behav Nutr Phys Act 5, 15 .

6. Bere E \& Klepp K-I (2005) Changes in accessibility and preferences predict children's future fruit and vegetable intake. Int J Behav Nutr Phys Act 2, 15.
7. Weber Cullen K, Baranowski T, Rittenberry L, Cosart C, Owens E, Hebert D \& de Moor C (2000) Socioenvironmental influences on children's fruit, juice and vegetable consumption as reported by parents: reliability and validity of measures. Public Health Nutr 3, 345-356.

8. Vereecken CA, Keukelier E \& Maes L (2004) Influence of mother's educational level on food parenting practices and food habits of young children. Appetite 43, 93-103.

9. Wardle J, Herrera ML, Cooke L \& Gibson EL (2003) Modifying children's food preferences: the effects of exposure and reward on acceptance of an unfamiliar vegetable. Eur J Clin Nutr 57, 341-348.

10. Birch LL, Zimmerman SI \& Hind H (1980) The influence of social-affective context on the formation of children's food preferences. Child Dev 51, 856-861.

11. Benton D (2004) Role of parents in the determination of the food preferences of children and the development of obesity. Int J Obes Relat Metab Disord 28, 858-869.

12. Fisher JO \& Birch LL (1999) Restricting access to palatable foods affects children's behavioral response, food selection, and intake. Am J Clin Nutr 69, 1264-1272.

13. Wardle J, Carnell S \& Cooke L (2005) Parental control over feeding and children's fruit and vegetable intake: how are they related? J Am Diet Assoc 105, 227-232.

14. Wardle J \& Huon G (2000) An experimental investigation of the influence of health information on children's taste preferences. Health Educ Res 15, 39-44.

15. Birch LL, Birch D, Marlin DW \& Kramer L (1982) Effects of instrumental consumption on children's food preference. Appetite 3, 125-134.

16. Galloway AT, Fiorito LM, Francis LA \& Birch LL (2006) 'Finish your soup': counterproductive effects of pressuring children to eat on intake and affect. Appetite $\mathbf{4 6}$, 318-323.

17. Horne PJ, Lowe CF, Bowdery M \& Egerton C (1998) The way to healthy eating for children. Br Food $J$ 100, 133-140.

18. Kremers SP, Brug J, de Vries H \& Engels RC (2003) Parenting style and adolescent fruit consumption. Appetite 41, 43-50.

19. Lowe CF, Horne PJ, Tapper K, Bowdery M \& Egerton C (2004) Effects of a peer modelling and rewards-based intervention to increase fruit and vegetable consumption in children. Eur J Clin Nutr 58, 510-522.

20. Wind M, De Bourdeaudhuij I, Te Velde SJ, Sandvik C, Due P, Klepp K-I \& Brug J (2006) Correlates of fruit and vegetable consumption among 11-year-old BelgianFlemish and Dutch schoolchildren. J Nutr Educ Behav 38, 211-221.

21. Pelchat ML \& Pliner P (1995) 'Try it. You'll like it.' Effects of information on willingness to try novel foods. Appetite 24, 153-165.

22. Pliner P \& Stallberg-White C (2000) 'Pass the ketchup, please': familiar flavors increase children's willingness to taste novel foods. Appetite 34, 95-103.

23. Darling N (1993) Parenting styles context: an integrative model. Psychol Bull 113, 487-496.

24. Birch LL, Fisher JO, Grimm-Thomas K, Markey CN, Sawyer R \& Johnson SL (2001) Confirmatory factor analysis of the Child Feeding Questionnaire: a measure of parental attitudes, beliefs and practices about child feeding and obesity proneness. Appetite 36, 201-210.

25. Hughes SO, Power TG, Orlet Fisher J, Mueller S \& Nicklas TA (2005) Revisiting a neglected construct: parenting styles in a child-feeding context. Appetite 44, 83-92.

26. Tibbs T, Haire-Joshu D, Schechtman KB, Brownson RC, Nanney MS, Houston C \& Auslander W (2001) The relationship between parental modeling, eating patterns, and dietary intake among African-American parents. $J \mathrm{Am}$ Diet Assoc 101, 535-541. 
27. Bogers RP, Van Assema P, Kester AD, Westerterp KR \& Dagnelie PC (2004) Reproducibility, validity, and responsiveness to change of a short questionnaire for measuring fruit and vegetable intake. Am J Epidemiol 159, 900-909.

28. Bogers RP (2005) Fruit and vegetable consumption. Measurement, determinants and interventions effects. Dissertation, University of Maastricht.

29. Liem DG, Bogers RP, Dagnelie PC \& de Graaf C (2006) Fruit consumption of boys ( $8-11$ years) is related to preferences for sour taste. Appetite 46, 93-96.

30. Donders-Engelen MR, Van der Heijden L \& Hulshof KFAM (2003) Maten, Gewichten en Codenummers 2003 (Portions, Weights and Code Numbers 2003). Zeist: Division of Human Nutrition, Wageningen University and TNO Nutrition.

31. Anon. (1998) Zo eet Nederland 1998. Resultaten van de Voedselconsumptiepeiling 1998 (Results of the Dutch National Food Consumption Survey 1998). The Hague: Voedingscentrum.

32. Kelley KM \& Behe BK (2003) Focus-group sessions suggest both kids and adults enjoy fresh carrots. HortTechnology 13, 393-394.

33. Cooke LJ \& Wardle J (2005) Age and gender differences in children's food preferences. BrJ Nutr 93, 741-746.

34. Guinard J-X (2000) Sensory and consumer testing with children. Trends Food Sci Technol 11, 273-283.

35. Hair J, Anderson R, Tatham R \& Black W (1998) Factor analysis. In Multivariate Data Analysis, 5th ed., pp. 87-138 [JHR Anderson, editor]. London: Prentice-Hall International.
36. Gibson EL, Wardle J \& Watts CJ (1998) Fruit and vegetable consumption, nutritional knowledge and beliefs in mothers and children. Appetite 31, 205-228.

37. Domel SB, Baranowski T, Davis H, Leonard SB, Riley P \& Baranowski J (1993) Measuring fruit and vegetable preferences among 4th- and 5th-grade students. Prev Med 22, 866-879.

38. Feunekes GI, Stafleu A, De Graaf C \& van Staveren WA (1997) Family resemblance in fat intake in The Netherlands. Eur J Clin Nutr 51, 793-799.

39. Ryan RM \& Deci EL (2000) Intrinsic and extrinsic motivations: classic definitions and new directions. Contemp Educ Psychol 25, 54-67.

40. De Graaf C, Cardello AV, Kramer FM, Lesher LL, Meiselman HL \& Schutz HG (2005) A comparison between liking ratings obtained under laboratory and field conditions: the role of choice. Appetite $\mathbf{4 4}, 15-22$.

41. Silvia PJ (2006) Reactance and the dynamics of disagreement: multiple paths from threatened freedom to resistance to persuasion. Eur J Soc Psychol 36, 673-685.

42. Hubbs-Tait L, Seacord Kennedy T, Page MC, Topham GL \& Harrist AW (2008) Parental feeding practices predict authoritative, authoritarian, and permissive parenting styles. J Am Diet Assoc 108, 1154-1161.

43. Irala-Estévez JD, Groth M, Johansson L, Oltersdorf U, Prättälä R \& Martínez-González MA (2000) A systematic review of socio-economic differences in food habits in Europe: consumption of fruit and vegetables. Eur J Clin Nutr 54, 706-714. 
Appendix 1

Factor structure for parent-reported parental child-feeding strategies for vegetables (V)

Factor 1: Positive information

$\begin{array}{ll}\text { Do you tell your child } V \text { are healthy? } & 0.81\end{array}$

$\begin{array}{ll}\text { Do you tell your child } V \text { are tasty? } & 0.81\end{array}$

Do you tell your child $V$ are good for them? $\quad 0.79$

$\begin{array}{ll}\text { When you eat } V \text {, do you show your child that you like them? } & 0.71\end{array}$

Factor 2: Distraction

Do you promise your child something tasty or nice, if he/she eats the $V$ ?

Do you stimulate $\mathrm{V}$ consumption by presenting $\mathrm{V}$ in an unrecognizable state?

Do you stimulate $\mathrm{V}$ consumption by making a game of eating $\mathrm{V}$ or telling a story around eating $\mathrm{V}$ ?

Do you tell your child that he/she won't get something tasty or nice, if he/she doesn't eat the V?

Factor 3: Choice

Do you give your child $V$ when he/she gets back from school?

Do you have a bowl with $V$ at home from which the child is allowed to take?

$0 \cdot 63$

Do you give your child $V$ to take with him/her to school?

Do you try to convince your child to eat $\mathrm{V}$ instead of cake or candy?

0.57

Do you let your child co-decide what $\mathrm{V}$ are eaten?

Factor 4: Negative atmosphere

Do you get frustrated when your child doesn't want to eat $V$ ?

Do you get angry when your child doesn't want to eat $V$ ?

Do you start a discussion when your child doesn't want to eat $V$ ?

Do you show your disapproval when your child doesn't want to eat $V$ ?

Factor 5: Pressure

When you give your child $\mathrm{V}$, does he/she have to eat the whole portion?

Do you make your child eat $\mathrm{V}$ when he/she doesn't want to?

Factor 6: Taste masking

Do you let your child add something else over the V?

Do you let your child add apple sauce over the $V$ ?

Do you let your child add warm sauce over the $V$ ?

Do you let your child add ketchup over the V?

Factor 7: Habit

Do you habitually have $\mathrm{V}$ available at home?

Do you eat $\mathrm{V}$ in the presence of your child?

Factor 8: Extra vegetables

Do you habitually serve different kinds of $\mathrm{V}$ at supper?

Do you prepare an extra type of $\mathrm{V}$, if your child doesn't like the offered $\mathrm{V}$ ?

Do you take a second serving of $V$ at dinner, in the presence of your child?

Parental practices not included in the factor structure

Do you compliment your child after eating V?

Do you offer $V$ as reward for good behaviour?

Do you serve $\mathrm{V}$ during celebration moments?

Do you tell your child that he/she should taste at least one bite, if he/she doesn't want to eat

$\checkmark$ at that moment?

Do you offer $V$ that your child does not like, later on again?

Do you set limits to the amount of $V$ your child is allowed to eat?

Do you monitor the amount of $\mathrm{V}$ your child eats?

Do you let your child assist in preparing $\mathrm{V}$ ?

Do you stimulate $\mathrm{V}$ consumption by preparing the $\mathrm{V}$ in alternative ways?

Do you stimulate $\mathrm{V}$ consumption by serving $\mathrm{V}$ in an attractive way?

Do you stimulate $V$ consumption by tricking the child? 
Appendix 2

Factor structure for parent-reported parental child-feeding strategies for fruit (F)

Factor 1: Negative atmosphere and Pressure

Do you start a discussion when your child doesn't want to eat F?

$0 \cdot 77$

Do you show your disapproval when your child doesn't want to eat F?

$0 \cdot 75$

Do you get angry when your child doesn't want to eat F?

Do you get frustrated when your child doesn't want to eat F?

Are you strict with your child concerning eating of $F$ ?

Do you make your child eat $F$ when he/she doesn't want to?

Do you tell your child that he/she won't get something tasty or nice if he/she doesn't eat F?

Do you promise your child something tasty or nice if he/she eats F?

0.65

0.62

0.62

Factor 2: Positive information*

Do you tell your child $F$ is healthy?

0.55

Do you tell your child $F$ is tasty?

Do you tell your child $F$ is good for them?

When you eat $F$, do you show your child that you like it?

$0 \cdot 75$

Factor 3: Distraction

Do you stimulate $\mathrm{F}$ consumption by making a game of eating $\mathrm{F}$ or telling a story around eating $\mathrm{F}$ ?

Do you stimulate $F$ consumption by presenting $F$ in an unrecognizable manner?

Do you stimulate $\mathrm{F}$ consumption by tricking your child?

Factor 4: Choice*

Do you have a bowl with $\mathrm{F}$ at home from which the child is allowed to take?

If you have different types of $F$ at home, is your child allowed to choose what kind of fruit he/she wants to eat? Do you serve fruit during celebration moments?

Do you let your child assist in preparing $F$ ?

Factor 5: Availability

Do you habitually have $\mathrm{F}$ available at home?

Do you habitually have different types of $F$ at home?

Parental practices not included in the factor structure

Do you compliment your child after eating $F$ ?

Do you offer $F$ as reward for good behaviour?

Do you eat $F$ in presence of your child?

When you offer your child $F$, should he/she eat the whole portion?

Do you tell your child that he/she should taste at least one bite, if he/she doesn't want to eat $F$ at that moment?

Do you offer $F$ that your child does not like, later on again?

Do you set limits to the amount of $F$ your child is allowed to eat?

Do you give your child $\mathrm{F}$ to take with him/her to school?

Do you give your child $F$ when he/she gets back from school?

Do you try to convince your child to eat $F$ instead of cake or candy?

Do you monitor the amount of $F$ your child eats?

Do you prepare $\mathrm{F}$ for your child, so he/she can eat it immediately?

Do you stimulate $F$ consumption by serving $F$ in an attractive way?

*For reasons of comparison, the items for this factor have been listed in the same order as for vegetables. 